\title{
Experiences with Work and Participation in Public Programs by Low-Income Medicaid Enrollees Using Qualitative Interviews
}

\author{
Alan Manivannan, BS ${ }^{7}$, Melissa Adkins-Hempel, BA ${ }^{2}$, Nathan D. Shippee, $P h D^{3}$, and \\ Katherine Diaz Vickery, MD, MSc ${ }^{1,2}$ (B)
}

'University of Minnesota Medical School631 SE Oak St, Minneapolis, MN, USA; ${ }^{2}$ Hennepin Healthcare Research Institute 701 Park Ave., S9. 104/S2.31 1, Minneapolis, MN, USA; ${ }^{3}$ University of Minnesota School of Public Health420 Delaware St. SE, MMC 729 Mayo, Minneapolis, MN, USA.

BACKGROUND: Centers for Medicare \& Medicaid Services (CMS) began encouraging governors to implement work requirements for Medicaid enrollees using section 1115 waivers in 2018. Significant controversy surrounds such attempts, but we know little about the perceptions and experiences of enrollees.

OBJECTIVE: To characterize experiences of work and its relationship to participation in Medicaid and other public programs among potential targets of Medicaid work requirements.

DESIGN: In-depth, semi-structured, one-time qualitative interviews.

PARTICIPANTS: 35 very low-income, non-disabled Medicaid expansion enrollees participating in a countysponsored Medicaid managed care plan as a part of a larger study.

APPROACH: We used a biographical narrative interpretive method during interviews including questions about the use of employment and income support and other public programs including from state and federal disability programs. Our team iteratively coded verbatim transcripts allowing for emergent themes.

KEY RESULTS: Interview data revealed high motivation for, and broad participation in, formal and informal paid work. Eight themes emerged: (1) critical poverty (for example, "I'm not content, but what choices do I have?"); (2) behavioral and physical health barriers to work; (3) social barriers: unstable housing, low education, criminal justice involvement; (4) work, pride, and shame; (5) inflexible, unstable work (for example, "Can I have a job that will accommodate my doctor appointments?...Will my therapy have to suffer? You know? So it's a double edged sword."); (6) Medicaid supports the ability to work; (7) lack of transparency and misalignment of program eligibility (for example, "It's not like I don't want to work because I would like to work. It's just that I don't want to be homeless again, right?"); and (8) barriers, confusion, and contradictions about federal disability.

Prior Presentations This research was shared as an oral presentation at the Minnesota Academy of Family Physicians Research and Innovation Day on May 2, 2019, and as a poster at the AcademyHealth 2019 Annual Research Meeting on June 3.2019.

Received December 18, 2019

Revised April 4, 2020

Accepted May 8, 2020

Published online May 29, 2020
CONCLUSIONS: We conclude that bipartisan solutions prioritizing the availability of well-paying jobs and planful transitions off of public programs would best serve very low-income, work-capable Medicaid enrollees.

KEY WORDS: Medicaid; work; poverty/income; social determinants of health.

J Gen Intern Med 35(10):2983-9

DOI: $10.1007 / \mathrm{s} 11606-020-05921-z$

(c) Society of General Internal Medicine 2020

\section{INTRODUCTION}

Centers for Medicare \& Medicaid Services (CMS) began encouraging governors to implement work requirements for Medicaid enrollees using section 1115 waivers in 2018. ${ }^{1}$ Since that time, as of March 2020, 20 states have submitted waivers requiring work, with six receiving approval and expressing intent to implement (UT, AZ, WI, SC, IN, OH). Four states have received approval but roll-outs have been stalled by courts (AR, KY, NH, MI). ${ }^{2}$

Work requirements have generated significant controversy. States implementing requirements describe their purpose as encouraging non-disabled, non-elderly enrollees to pursue and maintain employment. ${ }^{3}$ However, critics have suggested such mandates will prove harmful, ineffective, and inefficient. ${ }^{4}$ Furthermore, most Medicaid enrollees are expected to qualify for exemptions - most commonly because they are already working. $^{5-7}$ Work-qualifying activities and exemptions vary by state. Qualifying activities include formal employment, volunteering, job skills training/readiness, and substance use disorder (SUD) treatment (Michigan). Exemptions include caregiving, pregnancy, illness/disability, school, and inability to find work. Estimates suggest administrative costs may exceed savings for participating states. ${ }^{4} \mathrm{CMS}$ recently unveiled a block grant Medicaid funding strategy that may further fuel states to implement work requirements and tighten exemptions. $^{8}$

Qualitative interviews have previously examined enrollees gaining Medicaid and related self-perceived health and experiences accessing and using health care in Oregon. ${ }^{9,} 10$ Other research has combined interviews and surveys to measure the 
impact of Medicaid coverage on enrollees' ability to work and seek employment. ${ }^{11}$ However, we have found no studies using qualitative inquiry to more broadly describe the perceptions and experiences of Medicaid expansion enrollees in seeking and keeping formal employment. In this paper, we use indepth interview data from 35 very low-income, non-disabled early Medicaid expansion enrollees in Minnesota to describe their experiences of work and its relationship to participation in Medicaid and other public programs.

\section{METHODS}

\section{Sample}

We interviewed very low-income early Medicaid expansion enrollees participating in a county-sponsored Medicaid managed care plan as a part of a larger study. ${ }^{12}$ These Medicaid expansion enrollees, at the time, were adults without dependents earning $<75 \%$ of the federal poverty limit. While income-based Medicaid eligibility in Minnesota now matches the national average, Minnesota spends $\sim \$ 1500$ more than the US average per adult enrollee. ${ }^{13}$ Inclusion criteria required 24 months of continuous enrollment in the plan (during 20112014) and one or more visits at any of four core primary care clinics. We sent qualifying enrollees letters $(N=636)$ and made follow-up phone calls ( $N=29$ investigator-initiated, $N$ $=49$ participant-initiated). Participants received gift card compensation as well as transportation support (bus tokens or parking). We used purposive sampling and multiple rounds of recruitment to optimize representation of racial/ethnic minorities, women, and younger people, all underrepresented among initial letter respondents. ${ }^{11}$

\section{Data}

We conducted semi-structured interviews using a biographical narrative interpretive method. This method emphasizes a comprehensive understanding of a person's life, using framing questions that empower interviewees to direct their narratives uninterruptedly. ${ }^{12}$ Interview participants signed consent for access to their medical and social service records. ${ }^{12}$ Interviewers completed structured training. Question guides included physical and behavioral health conditions, social history, experience using health care and social services, work history, and use of employment and income support programs, including state and federal disability programs.

\section{Analysis}

We transcribed interviews verbatim and reviewed them for accuracy. Using repeated readings of the transcripts, we developed a preliminary code book related to themes about work. We applied the codes to a test set of transcripts in pairs and met to refine codebook themes/definitions and coding
Table 1 Demographics Characteristics of Interview Participants on Medicaid with Very Low Income

\begin{tabular}{|c|c|}
\hline & $\begin{array}{l}N= \\
35\end{array}$ \\
\hline \multicolumn{2}{|l|}{ Race, $n(\%)$} \\
\hline White & $\begin{array}{l}17 \\
(49)\end{array}$ \\
\hline African American & $\begin{array}{l}14 \\
(40)\end{array}$ \\
\hline American Indian & $3(9)$ \\
\hline Other & $1(3)$ \\
\hline \multicolumn{2}{|l|}{ Sex, $n(\%)$} \\
\hline Male & $\begin{array}{l}26 \\
(74)\end{array}$ \\
\hline Female & $9(26)$ \\
\hline \multicolumn{2}{|l|}{ Age range, $n(\%)$} \\
\hline $20-40$ & $3(9)$ \\
\hline $41-50$ & $\begin{array}{l}15 \\
(43)\end{array}$ \\
\hline $51-60$ & $\begin{array}{l}12 \\
(34)\end{array}$ \\
\hline $61-65$ & $5(14)$ \\
\hline \multicolumn{2}{|l|}{ Work history, $n(\%)$} \\
\hline No current or past employment & $1(3)$ \\
\hline History of work outside the study period & $8(23)$ \\
\hline $\begin{array}{l}\text { Informal labor, or participation in job-readiness program } \\
\text { during the study period }\end{array}$ & $7(20)$ \\
\hline Part-time job or minimal work during the study period & $\begin{array}{l}16 \\
(46)\end{array}$ \\
\hline Full-time job during the study period & $3(9)$ \\
\hline \multicolumn{2}{|l|}{ Social complexity } \\
\hline \multicolumn{2}{|l|}{ Contact with the criminal justice system, $n(\%)$} \\
\hline None & $\begin{array}{l}17 \\
(49)\end{array}$ \\
\hline $\begin{array}{l}\text { Historical stay in jail/prison; involvement with the criminal } \\
\text { justice system without stay }\end{array}$ & $\begin{array}{l}10 \\
(29)\end{array}$ \\
\hline Involvement with probation or diversionary court & $4(11)$ \\
\hline Some time spent in jail/prison during the study period & $4(11)$ \\
\hline $\begin{array}{l}\text { Substantial time spent in jail/prison or workhouse during the } \\
\text { study period }\end{array}$ & - \\
\hline \multicolumn{2}{|l|}{ Education, $n(\%)$} \\
\hline Never attended school & $1(3)$ \\
\hline Less than high school (HS) & $8(23)$ \\
\hline HS diploma or GED & $\begin{array}{l}16 \\
(46)\end{array}$ \\
\hline Some post-secondary education & $4(11)$ \\
\hline Unavailable & $6(17)$ \\
\hline \multicolumn{2}{|l|}{ Unstable housing, $n(\%)$} \\
\hline Chronically homeless & $1(3)$ \\
\hline Episodically homeless ${ }^{\dagger}$ & $5(14)$ \\
\hline Transitionally homeless & $1(3)$ \\
\hline Semi-stable housing ${ }^{\S}$ & $\begin{array}{l}14 \\
(40)\end{array}$ \\
\hline Very stable housing" & 13 \\
\hline Stable house or apartment ${ }^{\text {It }}$ & $1(3)$ \\
\hline
\end{tabular}

*Chronically homeless, "entrenched"27 in the shelter system, on the streets, or otherwise homeless for years

†Episodically homeless with frequent shuttling in and out of homelessness; often in/out of homes of family/friends, hospitals, chemical dependency programs, and/or criminal justice settings; a significant subjective sense of instability

$\ddagger$ Transitionally homeless short, often single use of shelter system, subjective description of brief, temporary, limited nature of homeless circumstance

${ }^{\xi}$ Semi-stable housing includes supportive and public housing or other similar programs and with subjective mention of possibility of housing situation ending due to behaviors (e.g., required sobriety); living with family members/friends but suggestion of volatile situation, or history of frequent moves

"Very stable situation without mention of subjective instability including public housing without monitoring of behavior

${ }^{\top}$ Stable house or apartment that you fully pay for by yourself ${ }^{2}$ 
practices across team members. Using the revised codebook, two team members coded each transcript in NVivo (version 11) software. Coding discrepancies were resolved in team meetings. We created analytic memos documenting early results and identifying new or unexpected (emergent) codes. We reapplied emergent codes and refined coding definitions to transcripts iteratively. ${ }^{14}$ As previously described, we used summaries of health conditions, work and criminal justice histories, and use of services to descriptively characterize participants. ${ }^{12}$

\section{RESULTS}

We interviewed 35 adults from October 2015 to April 2016. Forty-nine percent of participants were White, $40 \%$ Black, and 9\% American Indian (Table 1). Most $(n=26)$ were male. Our sample reflects the urban, nondisabled, childless adult subset of Minnesota's early Medicaid expansion (2011-2013). This subset was majority male and non-White, ${ }^{15}$ in contrast to the overall Minnesota's Medicaid population who are majority female and white. ${ }^{16,17}$ Participants had varied work histories during the study period; only three had had full-time employment. ${ }^{12}$

We identified eight themes related to work, which fit into three broad domains: (I) contexts of people's lives complicating their ability to work; (II) experiences with work; (III) experiences with public programs (Table 2).

\section{Context complicating work}

1. Critical poverty: "I'm not content, but what choices do I have?"

All participants described critical poverty-low/no income creating severe deprivation - by detailing their daily struggles meeting basic needs and "living check to check." This poverty had direct, if counterintuitive, relationships with work and participation in public programs including Medicaid. Many said things like, "I'd like to get off of that [assistance] and become more sufficient for myself." However, program designs created barriers to self-sufficiency (see 7.). Participants also described very small sums of assistance requiring critical spending decisions (e.g., rent, utilities, medications). Beyond public programs, some relied on assistance from, or gave assistance to, family or friends who also needed help creating a communal sense of stretching resources for survival. A few young and socially connected participants pooled resources and living spaces to meet basic needs and reduce the stress of poverty. For a minority of participants, critical poverty was exacerbated by substance use (see 2.).

\section{Behavioral and physical health barriers to work}

Participants described a complex intersection of physical and behavioral barriers to work. Behavioral health conditions (mental illness and/or SUD) were common, but not universal. Often conditions were un-/under-treated, creating difficulty

Table 2 Work-Related Themes and Definitions from People on Medicaid with Very Low Income

\begin{tabular}{|c|c|c|}
\hline & Theme & Definition \\
\hline $\begin{array}{l}\text { I. Context } \\
\text { complicating work }\end{array}$ & $\begin{array}{l}\text { 1. Critical poverty: "I'm not } \\
\text { content, but what choices do I } \\
\text { have?" } \\
\text { 2. Behavioral and physical } \\
\text { health barriers to work }\end{array}$ & $\begin{array}{l}\text { Critical poverty shared by all participants } \\
\text { limited life choices } \\
\text { Physical health conditions caused pain, } \\
\text { limited mobility, and other challenges that } \\
\text { limited work. Mental health and substance use } \\
\text { caused other barriers. }\end{array}$ \\
\hline
\end{tabular}

3. Social barriers: unstable housing, low education, criminal justice involvement

$\begin{array}{ll}\begin{array}{l}\text { II. Work } \\ \text { experience }\end{array} & \text { 4. Work, pride, and shame }\end{array}$

5. Inflexible, unstable work

III. Experience with public programs
6. Medicaid supports the ability to work

7. Lack of transparency and misalignment of program eligibility

8. Barriers, confusion, and contradictions about federal disability

Example quote

"With $\$ 97$ a month I have to be pretty creative in order to, you know, make it through to the next month."

"I cannot go back to waitressing as an alcoholic. Schlepping drinks was not a good idea for me."

"And I've done it [manual labor] but then I pay for days, you know."

"Once you lose a place, it's really hard to come up from that."

Unstable housing and homelessness, low educational attainment, and interactions with the criminal justice system further limited work options.

"I just got out of prison in [year] so it is kind of hard for a felon to try and get employment out here."

"I really, really, really want to work"

Desire for work is high and tied to self-worth. People seek formal and informal work to meet this need. Shame and stigma was expressed by those who were not working. Available work is limited and provides no time off for appointments, rarely are any benefits offered.

Health insurance is essential and needed to work or look for work

Participation in public programs relied on eligibility guidelines which were not transparent

Federal disability was sought by many but obtained by few. Complicated application processes, repeated denials, and inconsistent advice from different medical providers and courts caused frustration.
"Can I have a job that will accommodate my doctor appointments? You know? Will my therapy have to suffer? You know? So it's a double edged sword."

"It's crucial for me to maintain my health care so that plays a factor in me going out and actually finding a job."

"They're not going to tell you how much you can make though, right? So it is, it's a big trap."

"Yes, do all the hoops and still, after a couple of years, it is still the same thing and it is just stuck." 
maintaining schedules and routines needed to sustain employment. Specific concerns included the ineffectiveness of employment support programs that did not address behavioral health, cycles of increased income leading to substance use relapse and job loss, work settings exacerbating SUDs, and difficulty building sober/healthy social networks.

Some participants also struggled with sequelae of past trauma (e.g., gunshot wounds, domestic violence, neighborhood violence). Symptoms (e.g., poor sleep, irritability, hypervigilance) interfered with daily functioning. Multiple participants mentioned traumatic brain injuries impacting mood and cognition. Some isolated themselves to avoid personal or legal conflicts. Several noted that treatment is "a long process really."

Physical health barriers also limited the ability to work, even among relatively younger participants, including musculoskeletal injuries and pain (often chronic/recurring), asthma, falls and balance difficulties, and seizures. Participants described cycles of manual work triggering pain flares but had difficulty proving causality to employers and medical providers, which complicated disability assessments (see 8.). Physical health problems often led to missed work and sometimes loss of work and/or housing. Several participants described struggles with chronic pain leading to the use of/ cravings for substance use. Those with health barriers to work often described trade-offs of spending time working versus managing their many health conditions (attending appointments, getting/taking medications, etc.).

3. Social barriers: unstable housing, low education, criminal justice involvement

Related to critical poverty, most participants described significant social complexity (Table 1), which we have defined as social factors that increase the risk for poor health outcomes. ${ }^{12}$ Participants described how unstable housing, low education, and criminal justice involvement complicated finding and keeping work. Limited employment experience was also relevant (discussed below, (II) work experience). Most participants described some degree of unstable housing; seven had current or recent homelessness. Lack of housing and physical illness combined to make finding work harder; one participant explained, "[W]ith ulcerative colitis, it made it hard for me to work, and if you don't have an income, you don't have a place to live...You're gonna go downhill from there."

Nine participants (26\%) lacked a high school degree; sixteen $(46 \%)$ had a high school degree or G.E.D. Participants recognized the need for more training/education to improve work opportunities and achieve self-sufficiency, yet many struggled with costs and other requirements. One said, "I was taking some classes at [a local community college], and we ended up falling off for the semester. The semester ends and you try to get back in classes, but I tried to enroll, but they wouldn't let me back in so that was another obstacle that I had to overcome."
Half of the participants described interactions with the criminal justice system. Three individuals noted this was a barrier to work and higher education. One said: "I just got out of prison so it is kind of hard for a felon to try and get employment out here." Several participants noted that "little things all add up" and described frustration and disempowerment. For one, minor offenses (intoxication, illegal check cashing) were compounded by injuries, all presenting barriers to obtaining work. Another detailed the connections between SUD, related criminal justice involvement, and courtmandated treatment. Combined, these led to little time to find work and stigma from family and employers.

\section{Work experience}

4. Work, pride, and shame

Participants expressed pride and enthusiasm about work and voiced a strong desire to work more and re-enter the work force. One said, "If I could help with some of the finances by working, and that would help me too. Then I could get off welfare." Work, formal and informal, contributed to positive self-worth. Participants viewed work as an aspiration and a means to end-a mechanism to achieve financial independence from public assistance. Even those enrolled in federal disability aspired to return to work someday. Several believed they could increase their efforts ("up my game") to overcome barriers to working. Many utilized employment support agencies, supported by the Medicaid managed care plan common to all participants, ${ }^{18}$ for help building a resumé, finding appropriate interview clothes, or searching for work.

Lack of work contributed to shame and stigma for many. One said, "I was never really on a welfare mentality. I wasn't raised on that mentality." A minority of participants expressed fierce pride in self-sufficiency for not taking General Assistance ([GA], cash support) or having enrolled/managed the eligibility requirements for public programs on their own. Others described tension with friends and family due to participation in public programs. One participant described internalizing these perspectives: "My family ... they think of your worth as your employment status and so they're like, 'Well how did you get that? You don't work.'... I thought, 'I didn't earn it. I didn't do anything. I'm homeless. I haven't done anything. I didn't earn anything."”

\section{Inflexible, unstable work}

Participants described varied formal employment histories including masonry, carpentry, painting, landscaping, and maintenance. Others had informal work, including babysitting for family and friends or other "under the table" activities to earn some income while still remaining eligible for benefits. For example, one participant said, "If somebody need their grass cut, ...some leaves picked up, somebody need painting, you know, anything."

Despite some experience, finding employment was hard for most. Formal work histories included frequent part-time, 
seasonal positions, and short employment timelines. Participants said, "I work this job or that job" and "I'm just living day-to-day...trying to work anywhere." Unstable, low-paying work was exacerbated by critical poverty and the work of managing health conditions. Several participants described feeling overwhelmed or exhausted by the process of balancing work with the logistical demands of life and household duties, "I am working so that's the hours, which means things don't get clean."

Participants described discrimination and exploitation by employers related to homelessness and poverty: "I was there, what, 15 years or more...they cut my salary by 9,000 dollars a year... they told me to take it or leave it, so." Another said, "[T] he director said, 'Well, gee. If I would have known [name] was living in a shelter, I would have never hired him in the first place.' Right from the horse's mouth."

\section{Experience with public programs}

6. Medicaid supports the ability to work

Participants' enrollment in Medicaid related to their capacity to work in multiple ways. Health insurance was vital for several in providing their functional ability to work. This often related to access to medications (e.g., inhalers or mood-stabilizers) critical to maintaining health. One participant said, "Without insurance I wouldn't be able to obtain any of the medicine that I have been receiving, so, it is very important that I have insurance." Another, still looking for work, described, "When one inhaler costs $\$ 175$, I mean, it just wouldn't happen. You know?"

Participants also described the instability of income-based health insurance coverage, given their shifting employment status. Available formal work often did not include insurance coverage, leaving participants with the potential loss of coverage if their income exceeded Medicaid eligibility thresholds (see 5.). Some adjusted their hours to avoid loss of coverage; one asked himself, "How many hours can I work to satisfy the county to keep my medical?" Another noted being stuck in a gap wherein they no longer qualified for Medicaid because of a new job, but were not yet eligible for MinnesotaCare, a statewide program for near-poverty income earners. ${ }^{19}$ Without medication, this participant was "constantly sick" during the course of this period, leading to missed work, termination, and resumption of Medicaid coverage. This feeling of being "[stuck] between a rock and a hard place" was shared by many attempting to balance health care needs with the desire for work.

7. Lack of transparency and misalignment of program eligibility

Participants' concerns regarding administrative challenges and maintaining eligibility for benefits stretched beyond health insurance to state and federally supported programs for food and cash assistance and housing. General (cash) Assistance (GA) and Group Residential Housing (supportive housing) were described as critical resources. Many reflected on their struggle to survive on "\$97 a month" (the amount of GA left after rent deduction for supportive housing), leading them to ration basic needs like medication and toiletries.

Participants noted poor transparency regarding how much outside income would trigger loss of eligibility. One described it as trying to "put the puzzle pieces together." Others characterized their supported housing site as having a "no-work policy." Numerous participants described a lack of support for navigating in or out of benefits systems. One said, "It's not like I don't want to work because I would like to work. It's just that I don't want to be homeless again, right?" Some in these situations described depending on informal housing (not being named on leases) or informal, often unstable work (see 5.) arrangements.

8. Barriers, confusion, and contradictions about federal disability

Many participants dealt with daily physical and behavioral barriers to their ability to work (see 2.). During interviews, twenty-one participants discussed applying for social security (federal disability); most repeatedly emphasized the intense eligibility requirements and complicated administrative processes. Successful enrollees $(n=2)$ spent years working on a series of applications, multiple denials and appeals, and repeated appearances before judges. They did this while managing health care appointments and with substantial assistance from physicians and lawyers. One said, "I got denied two times, but like they always say, just keep going to your appointments and just keep following up with your doctors."

Participants who had been repeatedly denied federal disability applications expressed frustration and discouragement. Differences between their own beliefs and opinions of medical providers and lawyers often created distress and discord. A few expressed extreme frustration because their medical providers did not share their belief of being disabled. One said, "I don't know what I can do, and all along the doctors are like, 'We want to help you but we are not going to sign this paper or not going to give this opinion that you can't work.' So it has just been therapy this and therapy that and do this and do this. Yes, do all the hoops and still, after a couple of years, it is still the same thing and it is just stuck." Others wanted to work but felt their medical providers were holding them back. One described, "They told me not to work because that would be bad for my health. I look at it as, you know, I'm in good shape. I can breathe good, talk good, you know?" Participants sometimes received mixed messages from medical versus legal/ court systems. Such ambiguity led to frustration and anger and often consumed years of participants' lives.

\section{Interconnectedness of Themes}

As noted repeatedly above, deep interconnections between themes meant that challenges in individuals' experiences typically perpetuated or exacerbated each other. Participants' 
critical poverty contributed to premature morbidity, impacting physical and behavioral health - especially when combined with social barriers including unstable housing. These health and social barriers made getting and keeping work difficult, perpetuating critical poverty. These relationships were all exacerbated by misalignment and confusion regarding public programs.

\section{DISCUSSION}

In-depth interviews with 35 very low-income Medicaid enrollees revealed a high desire for work and deep connections between work and participants' health and self-worth. However, contextual factors including critical poverty, physical/behavioral health barriers, and social complexity made finding and keeping work difficult. Low-wage, temporary work often failed to cover basic living costs and neither offered insurance benefits nor accommodated appointments needed to maintain participants' physical and behavioral health. Furthermore, such work frequently lacked protection from discrimination due to health and social barriers. Perhaps most germane to our research aim, ever-changing eligibility requirements for Medicaid and other public programs created confusion and distress among most interview participants. Participants described risking insurance, income benefits, and housing when trying to fulfill their desire to work. These findings contribute rich, personal context to the current policy debate about Medicaid work requirements.

Our findings reinforce Tipirneni et al.'s findings regarding the role of stable insurance coverage and resultant good health as a precursor to work performance or to looking for work. ${ }^{11}$ Participants in our interviews emphasized that without health insurance they lacked the ability to fill prescriptions necessary for them to perform work. They described known gaps in medical insurance and other benefits in available, low-wage jobs. ${ }^{20}$ Several told stories of how interruptions in medical benefits led to a cascade of poor health, missed work, and lost wages - directly resulting in homelessness for some. Rather than work being a precursor for health insurance, these findings demonstrate that health is a necessary precursor to work. These findings, alongside Tiperneni et al., suggest that work requirements may be counterproductive for health and well-being, despite assertions to the contrary. ${ }^{21}$

Our study contributes to existing literature emphasizing the challenge of implementing work requirements on people incorrectly assumed to be "able-bodied." Ku and Brantley found that $48 \%$ of Medicaid expansion enrollees are permanently disabled or have serious physical and mental limitations. ${ }^{20}$ Unfortunately, our interview participants experienced substantial distress and ambiguity about whether or not they were disabled (see 8.). It is not clear in the current discussion of Medicaid work requirements how timely disability determinations will be made especially when considering the overburdened primary care system in the USA, ${ }^{22,23}$ a pattern that is especially prominent in many states considering work requirements. ${ }^{24}$
Our results reinforce literature documenting that people with very low income ( $<75 \%$ federal poverty) already face substantial administrative burdens ${ }^{25}$ and confusion about their Medicaid coverage. ${ }^{10}$ Work requirements will likely worsen the administrative barriers (see 7.) already faced by people with very low income and further complicate access to public programs. This is confirmed by Sommers et al.'s finding of widespread confusion among people impacted by Arkansas' attempt to implement work requirements. ${ }^{26}$

Our work has several limitations: first, our sample of enrollees from one Medicaid plan in one Midwestern urban region in a state with above-average per-enrollee Medicaid spending may not be generalizable to other regions. ${ }^{13}$ Second, although we corroborated interviews with data from health and social service records, self-reported data may be subject to social desirability bias especially when discussing sensitive topics such as criminal justice involvement and SUD. Third, our sample included mostly males without dependents, limiting our ability to consider implications for women and families. However, while study design may limit generalizability, we expect many key findings (e.g., health/social barriers, poverty, programs' lack of transparency and alignment) relate to the experiences of other adult Medicaid enrollees.

Policy recommendations informed by our research findings include:

1. More jobs and job training/education programs are needed that offer livable wages, insurance benefits, flexible schedules, and accommodations for people with physical and behavioral health barriers.

2. Future policy should consider administrative burdens of proposed work requirements. Current approaches stand to add significant confusion to participants who already face high levels of confusion and frustration.

3. Public programs (especially health insurance and housing) need transparent eligibility criteria and more flexible disenrollment procedures that do not interrupt services. Other regions could consider supplementary statesponsored insurance for those earning higher than Medicaid eligibility thresholds. ${ }^{19}$

In conclusion, rather than focusing on work requirements and other policies rooted in partisan politics, bipartisan solutions prioritizing availability of well-paying jobs and planful transitions off of public programs would best serve very lowincome, work-capable Medicaid enrollees.

Corresponding Author: Katherine Diaz Vickery, MD, MSc; Hennepin Healthcare Research Institute 701 Park Ave., S9.104/S2.311, Minneapolis, MN 55415, USA (e-mail: Katherine.Vickery@hcmed.org).

Funding Information Data collection for this manuscript was supported by a grant from the Commonwealth Fund (\#20140726). The participation of Dr. Vickery was supported by the National Institute of Diabetes and Digestive and Kidney Diseases of the National Institutes of Health under Award Number K23DK118117. 


\section{Compliance with Ethical Standards:}

Conflict of Interest: The authors declare that they do not have a conflict of interest.

Disclaimer: The content is solely the responsibility of the author and does not necessarily represent the official views of the National Institutes of Health.

\section{REFERENCES}

1. Center for Medicaid and Chip Services. RE: Opportunities to promote work and community engagement among Medicaid beneficiaries. 2018 https://www.medicaid.gov/federal-policy-guidance/downloads / smd18002.pdf.

2. Medicaid Waiver Tracker: Which states have approved and pending section 1115 Medicaid waivers? Henry J Kais Fam Found. 2019 https://www.kff.org/medicaid/issue-brief/which-states-have-approvedand-pending-section-1115-medicaid-waivers/.

3. Rosenbaum S, Somodevilla A, Handley M, Brim E, Brantley E. Medicaid work requirements meet the D.C. circuit. Health Aff Blog. 2019. https:// doi.org/10.1377/hblog20191025.796704/full/.

4. Carroll AE. The problem with work requirements for Medicaid. JAMA. 2018;319(7):646. doi:https://doi.org/10.1001/jama.2018.0420

5. Musumeci M, Garfield R, Rudowitz R. Medicaid and work requirements: New guidance, state waiver details and key issues. 2018:4.

6. Sommers BD, Fry CE, Blendon RJ, Epstein AM. New approaches in Medicaid: Work requirements, health savings accounts, and health care access. Health Aff (Millwood). 2018;37(7):1099-1108. doi:https://doi. org/10.1377/hlthaff.2018.0331

7. Tipirneni R, Goold SD, Ayanian JZ. Employment status and health characteristics of adults with expanded Medicaid coverage in Michigan. JAMA Intern Med. 2018;178(4):564. doi:https://doi.org/10.1001/ jamainternmed.2017.7055

8. Simmons-Duffin S. Trump Administration Clears the Way for Medicaid Block Grants. Natl Public Radio. 2020. https://www.npr.org/sections/ health-shots/2020/01/30/800841612/trump-administration-offersstates-a-way-to-block-grant-medicaid.

9. Allen H, Wright B, Broffman L. The impacts of Medicaid expansion on rural low-income adults: Lessons from the Oregon Health Insurance Experiment. Med Care Res Rev. 2018;75(3):354-383.

10. Allen H, Wright BJ, Baicker K. New Medicaid enrollees in Oregon report health care successes and challenges. Health Aff (Millwood). 2014;33(2):292-299. doi:https://doi.org/10.1377/hlthaff.2013.1002

11. Tipirneni R, Kullgren JT, Ayanian JZ, et al. Changes in health and ability to work among Medicaid expansion enrollees: A mixed methods study. J Gen Intern Med. 2019;34(2):272-280. doi:https://doi.org/10.1007/ s11606-018-4736-8

12. Vickery KD, Shippee ND, Guzman-Corrales LM, et al. Changes in quality of life among enrollees in Hennepin Health: A Medicaid expansion ACO. Med Care Res Rev. 2018:25.

13. State Health Facts: Medicaid Spending per Enrollee (Full or Partial Benefit). Henry J Kais Fam Found. 2017. https://www.kff.org/medicaid/state-indicator/medicaid-spending-per-enrollee/.
14. Creswell JW. Qualitative Inquiry and Research Design: Choosing among Five Approaches. 3rd ed. Los Angeles: SAGE Publications; 2013.

15. Shippee ND, Vickery KD. The Complex Needs of Medicaid Expansion Enrollees with Very Low Incomes. The Commonwealth Fund; 2018. https://www.commonwealthfund.org/publications/issue-briefs/2018/ may/complex-needs-medicaid-expansion-enrollees-very-low-incomes.

16. State Health Facts: Medicaid Enrollment by Gender. Henry J Kais Fam Found. 2017. https://www.kff.org/medicaid/state-indicator/medicaidenrollment-by-gender /?currentTimeframe=0\&sortModel=\%7B $\% 22$ colld \%22:\%22Location\%22,\%22sort\%22:\%22asc\%22\%7D\#.

17. State Health Facts: Medicaid Enrollment by Race/Ethnicity. Henry J Kais Fam Found. 2017. https://www.kff.org/medicaid/state-indicator/medicaid-enrollment-by-raceethnicity/?currentTimeframe=0\&sortModel $=\% 7 \mathrm{~B} \% 22$ colId $\% 22: \% 22$ Location $\% 22, \% 22$ sort $\% 22: \% 22$ asc $\% 22 \% 7 \mathrm{D}$.

18. Sandberg SF, Erikson C, Owen R, et al. Hennepin Health: A safety-net accountable care organization for the expanded Medicaid population. Health Aff Proj Hope. 2014;33(11):1975-1984. doi:https://doi.org/10. 1377 /hlthaff.2014.0648

19. Minnesota Department of Human Services. MinnesotaCare Program Info. 2019. https://mn.gov/dhs/people-we-serve/adults/health-care/healthcare-programs/programs-and-services/minnesotacare.jsp.

20. Ku L, Brantley E. Myths about the Medicaid expansion and the "ablebodied." Health Aff Blog. 2017. https://doi.org/10.1377/ hblog20170306.059021/full/.

21. Galewitz P. 5 Things to Know About Medicaid Work Requirements. Kais Health News. https://khn.org/news/5-things-to-know-about-medicaidwork-requirements/.

22. Bodenheimer T, Chen E, Bennett HD. Confronting the growing burden of chronic disease: Can the U.S. health care workforce do the job? Health Aff (Millwood). 2009;28(1):64-74. doi:https://doi.org/10.1377/hlthaff.28.1.

23. Petterson SM, Liaw WR, Phillips RL, Rabin DL, Meyers DS, Bazemore AW. Projecting US primary care physician workforce needs: 2010-2025. Ann Fam Med. 2012;10(6):503-509. doi:https://doi.org/10.1370/afm.1431

24. Health Resources and Services Administration Bureau of Health Workforce. State-Level Projections of Supply and Demand for Primary Care Practitioners: 2013-2025. U.S. Department of Health and Human Services; 2016:37. https://bhw.hrsa.gov/sites/default/files/bhw/ health-workforce-analysis/research/projections/primary-care-state-projections2013-2025.pdf.

25. Hill I, Burroughs E. Lessons from Launching Medicaid Work Requirements in Arkansas. Washington, DC: Urban Institute; 2019. https:// www.urban.org/sites/default/files/publication/101113/lessons_from launching medicaid work requirements in arkansas 4.pdf.

26. Sommers BD, Goldman AL, Blendon RJ, Orav EJ, Epstein AM. Medicaid work requirements - Results from the first year in Arkansas. N Engl J Med. 2019:doi:https://doi.org/10.1056/NEJMsr1901772

27. Kuhn R, Culhane DP. Applying cluster analysis to test a typology of homelessness by pattern of shelter utilization: results from the analysis of administrative data. Am J Community Psychol. 1998;26(2):207-232.

Publisher's Note: Springer Nature remains neutral with regard to jurisdictional claims in published maps and institutional affiliations. 